\title{
Homogeneity and Multiplicity Forms of Glandular Kallikreins
}

\author{
Yoshio Hojima, Yoshifumi Matsuda, Chiaki Moriwaki \\ and Hiroshi MORIYA \\ Faculty of Pharmaceutical Sciences, Science University of Tokyo ${ }^{1)}$
}

(Received October 23, 1974)

\begin{abstract}
Three preparations of hog pancreatic kallikrein (Hog Panc. K.) were applied to Ampholine isoelectric focusing. Each of them were separated into 5-6 kallikrein components with slightly different pI's in the range of $\mathrm{pH} 3.7-4.2$. The migration distances of these components in disc electrophoresis ( $\mathrm{pH} 8.9,7 \%$ polyacrylamide gel) were not distinguishable. Relating to these results, it was suggested that isoelectric focusing or gel isoelectrofocusing would be preferable to disc electrophoresis for the examination of the real homogeneity of Hog Panc. $K$. and other glandular kallikreins.

It was found by isoelectric focusing that human urinary kallikrein consisted of $3-5$ components with pI 3.8-4.3. On the other hand, human salivary kallikrein seemed to be composed of one component with pI 4.2.
\end{abstract}

Many investigators have purified and characterized glandular kallikreins from various sources, and some ones have presented the multiplicity of some kallikreins. Particularly, the multiplicity of glandular kallikrein has been observed on hog pancreatic kallikrein (Hog Panc. K.). Moriya and Shimazawa ${ }^{2)}$ were the first to report and Habermann ${ }^{3)}$ was the first to separate two multiple forms of Hog Panc. K. At present the occurrence of the kallikrein in a multiplicity of forms has been widely recognized by Werle and coworkers, ${ }^{4)}$ Takami, ${ }^{5}$ Moriya, ${ }^{6)}$ and Kutzbach and Schmidt-Kastner. ${ }^{7)}$ On the other hand, Moriya, et al. ${ }^{8)}$ reported a single highly purified form of Hog Panc. $\mathrm{K}$.

In this paper, the multiplicity of forms of Hog Panc. $\mathrm{K}$. is examined mainly by the technique of isoelectric focusing, and so as to make clear the above situation of Hog Panc. K., some opinions for its homogeneity are presented. In addition, some aspects for human urinary kallikrein (HUK) and human salivary kallikrein (HSK) are described.

\section{Material and Method}

Enzymes - A partially purified preparation of Hog Panc. K. (KY-3, $109 \mathrm{KU} / \mathrm{mg}$ ) was obtained by the acrinol method of Moriya, et al. $\left.{ }^{9}\right)$ Highly purified Hog Panc. K. (KK-2, $\left.813 \mathrm{KU} / \mathrm{ml}, 1186 \mathrm{KU} / A_{280}\right)$ was prepared by the previous method. ${ }^{8 c}$ ) Another highly purified preparation of Hog Panc. K. (KZC-150, 998 $\mathrm{KU} / \mathrm{mg}$; purified from Padutin) ${ }^{7}$ was kindly supplied from Drs. C. Kutzbach and G. Schmidt-Kastner, Bayer AG. The vasodilator activity of this prepartion had been estimated by their assay system to be $1250 \mathrm{KU} / \mathrm{mg}$ from its esterolytic activity on $\mathrm{N}^{\alpha}$-benzoyl-L-arginine ethyl ester (BAEE); however, comparison

1) Location: 12, Ichigaya-Funagawara-machi, Shinjuku-ku, Tokyo.

2) H. Moriya and E. Shimazawa, Yakugaku Zasshi, 79, 374 (1959).

3) E. Habermann, Z. Physiol. Chem., 328, 15 (1962).

4) a) F. Fiedler and E. Werle, Z. Physiol. Chem., 348, 1087 (1967); b) H. Fritz, I. Eckert and E. Werle, ibid., 348, $1120(1967)$; c) F. Fiedler, C. Hirschauer and E. Werle, ibid., 351, 225 (1970).

5) T. Takami, Seikagaku, 41, 777 (1969).

6) H. Moriya, J. Japan. Med. Assoc., 63, 932 (1970).

7) C. Kutzbach and G. Schmidt-Kastner, Z. Physiol. Chem., 353, 1099 (1972).

8) a) H. Moriya, Yakugaku Zasshi, 79, 1451 (1959); b) H. Moriya, J.V. Pierce and M.E. Webster, Ann. N.Y. Acad. Sci., 104, 172 (1963); c) H. Moriya, A. Kato and H. Fukushima, Biochem. Pharmacol., 18, 549 (1969).

9) a) H. Moriya, K. Yamazaki, H. Fukushima and C. Moriwaki, J. Biochem. (Tokyo), 58, 208 (1965); b) H. Moriya, Yakugaku Zasshi, 79, 32 (1959). 
with a standard kallikrein in our dog vasodilator assay ${ }^{10}$ ) showed it to be $998 \mathrm{KU} / \mathrm{mg}$. Purification procedures for HUK and HSK are described later.

Bovine trypsin (twice cryst., salt-free) was purchased from Sigma Chem. Co., and bovine $\alpha$-chymotrypsin (cryst., salt-free) was kindly supplied by Eisai Co., Ltd., Tokyo.

Chemicals_-BAEE, $\mathrm{N}^{\alpha}-p$-toluenesulfonyl-L-arginine methyl ester (TAME), $\mathrm{N}^{\alpha}$-benzoyl-DL-arginine-pnitroanilide (BApNA), and N-benzoyl-L-tyrosine ethyl ester (BTEE) were obtained from Protein Research Foundation (Minoh, Osaka), Calbiochem., Sigma, and Calbiochem., respectively. Hammarsten casein was obtained from E. Merck AG.

Ampholine carrier ampholytes ( $\mathrm{pH} 3-5$ ), acrylamide, riboflavine, and coomassie brilliant blue were purchased from L.KB-Produkter AB, Seikagaku Kogyo Co., Ltd., Canal Industrial Corp., and Sigma, respectively. Diethylaminoethyl (DEAE)-cellulose $(0.94 \mathrm{mEq} / \mathrm{g})$ was a product of Tohoku Pulp Co., Ltd. Sephadex G-25, G-75 and G-100 were products of Pharmacia. Hydroxyapatite was prepared according to the method of Levine. ${ }^{11)}$ Other chemicals used were of guaranteed reagent.

Vasodilator Assay_- The vasodilator activity of kallikreins and other enzymes was determined by the increase of blood flow at the dog femoral artery, being compared with that of a standard kallikrein (hog pancreatic, $23.25 \mathrm{KU} / \mathrm{mg}$ ). ${ }^{10 b}$ ) This activity is expressed in kallikrein units (KU).

Esterolytic Assay_-Esterolytic activities of enzymes on synthetic substrates, BAEE, TAME, BApNA and BTEE, were determined at $25^{\circ}$ in $0.05 \mathrm{M}$ Tris- $\mathrm{HCl}$ ( $\mathrm{pH} 8.0$ ). The assays were carried out according to the method of Schwert and Takenaka for BAEE, ${ }^{12)}$ those of Hummel for TAME and BTEE, ${ }^{13}$ and that of Trautschold for BApNA, ${ }^{14}$ ) measuring the increase of absorbances at $253,247,256$, and $405 \mathrm{~nm}$ respectively by a Hitachi spectrophotometer model EPU-2A. The amount of substrate hydrolyzed is denoted as $\mu$ mole/ min. Calcium chloride was added in the assay mediums for trypsin and $\alpha$-chymotrypsin.

Caseinolytic Assay-Caseinolysis was performed at $35^{\circ}$ by the method of Kunitz. ${ }^{15)}$ The activity is expressed in Kunitz's unit, [TU $]_{m g}^{\text {eas. }}$.

Determination of Protein Concentration-Protein concentration was determined from the absorbance at $280 \mathrm{~nm}$, using the above Hitachi spectrophotometer and quartz cells with an optical path length of $1 \mathrm{~cm}$.

Disc Electrophoresis - This was performed with $7 \%(\mathrm{w} / \mathrm{v})$ polyacrylamide gel and Tris-glycine buffer system (pH 8.9) according to the method of Davis, ${ }^{16}$ ) using an equipment of Hayashi Sci. Indust. Co., Ltd., Tokyo. The run was done with $2 \mathrm{~mA}$ per tube $(0.5 \times 8.5 \mathrm{~cm})$ for $1.5 \mathrm{hr}$ at $4^{\circ}$. After run, the gels were stained with $0.01 \%(\mathrm{w} / \mathrm{v})$ coomassie brilliant blue dissolved in $10 \%(\mathrm{w} / \mathrm{v})$ trichloroacetic acid.

Isoelectric Focusing_-Ampholine carrier ampholytes $[1 \%(\mathrm{w} / \mathrm{v})$ final concentration] with a $\mathrm{pH}$ range of 3-5 were employed with an LKB Ampholine column (110 ml, LKB-Produkter AB) according to the method of Vesterberg and Svensson. ${ }^{17}$ Samples were applied to the middle position of the sucrose gradient formed in the column. Electrophoresis was done for 24 or $48 \mathrm{hr}$ at 400 or $500 \mathrm{~V}$ under regulated temperature $\left(4^{\circ}\right.$ or $\left.10^{\circ}\right)$. Afterward, the column content was fractionated into 1.1 or $2 \mathrm{ml}$ portions, and the $\mathrm{pH}$ of each fraction was measured at the regulated temperature by a Hitachi-Horiba $\mathrm{pH}$ meter (F-5) with a Horiba 6028-10 T combined electrode attached. Then, one or two volumes of Tris-HCl $(0.2$ or $0.3 \mathrm{M}, \mathrm{pH} 8.0)$ were added into each fraction, and the absorbance at $280 \mathrm{~nm}$ of the fractions was measured at room temperature. Absorbance $\left(A_{280}\right)$ and kallikrein activity in the Figures are those of the original eluate.

Gel Isoelectrofocusing-_- Seven percents $(\mathrm{w} / \mathrm{v})$ polyacrylamide gels $(0.5 \times 6.8 \mathrm{~cm})$ containing $1 \%(\mathrm{w} / \mathrm{v})$ Ampholine ( $\mathrm{pH} 3-5$ ) were made with the following mixture: $28 \%(\mathrm{w} / \mathrm{v})$ acrylamide [contained $0.8 \%(\mathrm{w} / \mathrm{v})$ $\mathrm{N}, \mathrm{N}^{\prime}$-methylene-bis-acrylamide], $0.004 \%(\mathrm{w} / \mathrm{v})$ riboflavine, $8 \%(\mathrm{w} / \mathrm{v})$ Ampholine and water with the ratio of $2: 1: 1: 4$. After gel formation under fluorescent light, the same mixture contained sample was layered on the gel with the height of $1.5 \mathrm{~cm}$, and gellified in the same manner. The sample gel was further covered with the same mixture with the height of $0.2 \mathrm{~cm}$. As electrode solutions, $0.2 \%(\mathrm{v} / \mathrm{v})$ phosphoric acid and $0.4 \%(\mathrm{v} / \mathrm{v})$ ethylenediamine were used in the anode and in the cathode respectively. Isoelectrofocusing was carried out for $6.5 \mathrm{hr}$ at $4^{\circ}$ and $250 \mathrm{~V}$. After focusing, the gels were.washed for $24 \mathrm{hr}$ with $10 \%$ (w/v) trichloroacetic acid and stained with $0.01 \%(\mathrm{w} / \mathrm{v})$ coomassie brilliant blue.

10) a) H. Moriya, K. Yamazaki and H. Fukushima, J. Biochem. (Tokyo), 58, 201 (1965); b) C. Moriwaki, Y. Hojima and H. Moriya, Chem. Pharm. Bull. (Tokyo), 22, 975 (1974).

11) O. Levine, "Methods in Enzymology," Vol. V, ed. by S.P. Colowick and N.O. Kaplan, Academic Press Inc., New York, N.Y., 1962, p. 27.

12) G.W. Schwert and Y. Takenaka, Biochim. Biophys. Acta, 16, 570 (1955).

13) B.C.W. Hummel, Can. J. Biochem. Physiol., 37, 1393 (1959).

14) I. Trautschold, "Handbook of Experimental Pharmacology," Vol. XXV, ed. by E.G. Erdös, SpringerVerlag, Berlin, 1970, p. 52.

15) M. Kunitz, J. Gen. Physiol., 30, 291 (1947).

16) B.J. Davis, Ann. N.Y. Acad. Sci., 121, 404 (1964).

17) O. Vesterberg and H. Svensson, Acta Chem. Scand., 20, 820 (1966). 
Preparation of HUK___ Two kinds of the partially purified preparation of HUK were obtained by the different methods from that of Moriya, et al. ${ }^{80}$ ) All of the following chromatographic studies were performed at $4^{\circ}$ with a flow rate of $10-20 \mathrm{ml} / \mathrm{hr}$, and other procedures done at less than $10^{\circ}$.

A crude preparation of HUK $\left(0.64 \mathrm{KU} / \mathrm{mg}\right.$, supplied from Green Cross Corp., Osaka), $\left.{ }^{10 b}\right) 1.89 \mathrm{~g}$, was dissolved in $54 \mathrm{ml}$ of $0.02 \mathrm{M}$ phosphate buffer $\left(\mathrm{K}-\mathrm{Na}_{2}, \mathrm{pH} 7.0\right)$, and dialyzed overnight against the same buffer. After that, the dialysate was applied to a DEAE-cellulose column $(2.5 \times 42 \mathrm{~cm})$ equilibrated with the same buffer. HUK adsorbed to DEAE-cellulose was eluted by the gradient formed by adding $0.02 \mathrm{M}$ phosphate ( $\mathrm{pH} 7.0)-1 \mathrm{M} \mathrm{NaCl}$ to $500 \mathrm{ml}$ of the $0.02 \mathrm{M}$ phosphate buffer in a constant-volume mixing chamber. The active fractions checked by the dog assay were pooled $(102 \mathrm{ml})$ and concentrated to $9.7 \mathrm{ml}$ in a cellulose tubing (size: $36 / 32$, Visking Co.) by air-drying. The sample was then filtered through a Sephadex G-100 column $(1.5 \times 76 \mathrm{~cm}$, equilibrated with $0.01 \mathrm{~m}$ ammonium formate, $\mathrm{pH} 6.0)$. Active fractions were pooled and lyophilized after dialysis against deionized water. Lyophilized powder $(175 \mathrm{mg})$ showed the activity of $2.5 \mathrm{KU} / \mathrm{mg}$. An aliquot of this preparation was submitted to isoelectric focusing (see Result). [Before lyophilization, the dialysate (total, $157 A_{280}$ ) had a specific activity of $6.5 \mathrm{KU} / A_{280}$. So HUK lost a part of its activity during lyophilization.]

The further purification of HUK was attempted as follows. The lyophilized powder (132 mg, obtained as described above from $1.63 \mathrm{~g}$ of the crude preparation of $\mathrm{HUK}$ ) was dissolved in $1.7 \mathrm{ml}$ of $0.01 \mathrm{~m}$ phosphate buffer $\left(\mathrm{Na}-\mathrm{Na}_{2}, \mathrm{pH} 6.8\right)$, and applied to a hydroxyapatite column $(1.5 \times 6.5 \mathrm{~cm})$ equilibrated with the same buffer. In order to elute HUK, a gradient elution was formed by adding $0.15 \mathrm{~m}$ phosphate buffer (pH 6.8) to $300 \mathrm{ml}$ of the starting buffer in a constant-volume mixing chamber. The combined vasodilator fractions $(21 \mathrm{ml})$ were dialyzed against deionized water, then concentrated to $1.6 \mathrm{ml}$, and filtered through a Sephadex G-75 column $(1.5 \times 79 \mathrm{~cm})$ equilibrated with water. The active fractions whose mean $\mathrm{KU} / A_{280}$ was 42.5 were pooled and lyophilized. This preparation $(4.7 \mathrm{mg})$ had the activity of $22.5 \mathrm{KU} / \mathrm{mg}$. It was used for the disc electrophoresis and the substrate specificity experiment.

Preparation of Highly Purified HSK-HSK was prepared by the following simpler method than the previously reported. ${ }^{10 a, 18}$ Into $1800 \mathrm{ml}$ of human mixed saliva $\left(1.2 \mathrm{KU} / \mathrm{ml}, 3.2 A_{280} / \mathrm{ml}\right)$, whose insoluble materials had been removed, three volumes of acetone were added dropwise. The formed precipitates were collected by centrifugation and washed with acetone three times. The dried powder was dissolved in 18 liters of deionized water, and $18 \mathrm{~g}$ of DEAE-cellulose were added to the solution. The mixture was stirred for $1.5 \mathrm{hr}$ at $\mathrm{pH} 6.8$ and room temperature. The DEAE-cellulose collected on a glass-filter was washed with $0.1 \mathrm{M}$ ammonium formate ( $\mathrm{pH}$. 6.0) to remove other proteins, and then the HSK was eluted with $0.6 \mathrm{M}$ ammonium formate $(\mathrm{pH} 6.0)$. The eluate $(110 \mathrm{ml})$ was packed in a cellulose tubing, dialyzed against water for several hours, and concentrated to $29 \mathrm{ml}$ by air-drying at room temperature. The sample was then applied to a column of Sephadex G-100 $(2.5 \times 90 \mathrm{~cm})$ equilibrated with $0.01 \mathrm{M}$ ammonium formate $(\mathrm{pH} 6.0)$. The filtration was done at a flow rate of $15 \mathrm{ml} / \mathrm{hr}$ and $4^{\circ}$. The pooled fractions $(23.2 \mathrm{ml})$ had strong vasodilator activity $\left(45 \mathrm{KU} / \mathrm{ml}, 0.69 A_{280} / \mathrm{ml}\right.$ ). This was concentrated to $6.3 \mathrm{ml}$ and subjected to Ampholine isoelectric focusing for further purification (see Result).

\section{Result}

\section{Isoelectric Focusings of Three Different Preparations of Hog Panc. $\mathbf{K}$.}

Patterns of isoelectric focusing of KY-3, KK-2 and KZC-150 are shown in Fig. 1-3, respectively, and those of disc electrophoresis in Fig. 4 (A, C and D). The latter two preparations appeared to be homogeneous in disc electrophoresis. However, as shown in Fig. 1-3, their activities were divided into several peaks. The following results indicate that these peaks were not artifacts of the procedure, but were due to several components of Hog Panc. K. with slightly different pI's. The vasodilator activities of these peaks were almost in proportion to the esterolytic activities, and both activities were inhibited by Trasylol (kallikreintrypsin inhibitor from bovine organs, Bayer ${ }^{19}$ and by two kinds of kallikrein inhibitor from potatoes. ${ }^{20)}$ Therefore, it would be concluded that these preparations contain $5-6$ multiple components of Hog Panc. K. and that these components are present in the sharp, distinct protein bands shown in Fig. 4 (A, C and D).

18) a) Y. Fujimoto, H. Moriya and C. Moriwaki, J. Biochem. (Tokyo), 74, 239 (1973); b) Y. Fujimoto, C. Moriwaki and H. Moriya, ibid., 74, 247 (1973).

19) I. Trautschold, E. Werle and G. Zickgraf-Rüdel, Arzneim.-Forsch., 16, 1507 (1966).

20) Y. Hojima, C. Moriwaki and H. Moriya, J. Biochem. (Tokyo), 73, 923 (1973); idem, ibid., 73, 933 (1973). 


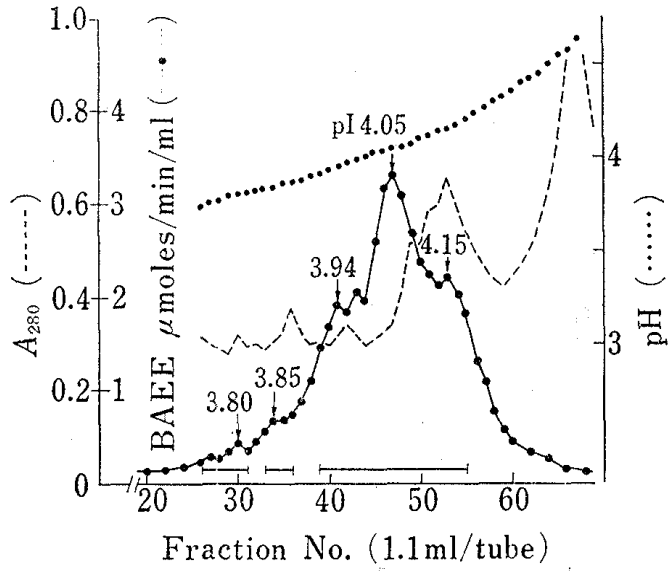

Fig. 1. Isoelectric Focusing of a Preparation of Hog Panc. K., KY-3

KY-3: $7.5 \mathrm{mg}$ (109 KU/mg, 11 BAEE $\mu$ moles! $\mathrm{min} / \mathrm{mg}$ ), Ampholine: $\mathrm{pH} 3-5,1 \%(\mathrm{w} / \mathrm{v})$, focusing: $500 \mathrm{~V}, 24 \mathrm{hr}, 4^{\circ}$

The activity recovery from the focusing was $91 \%$.

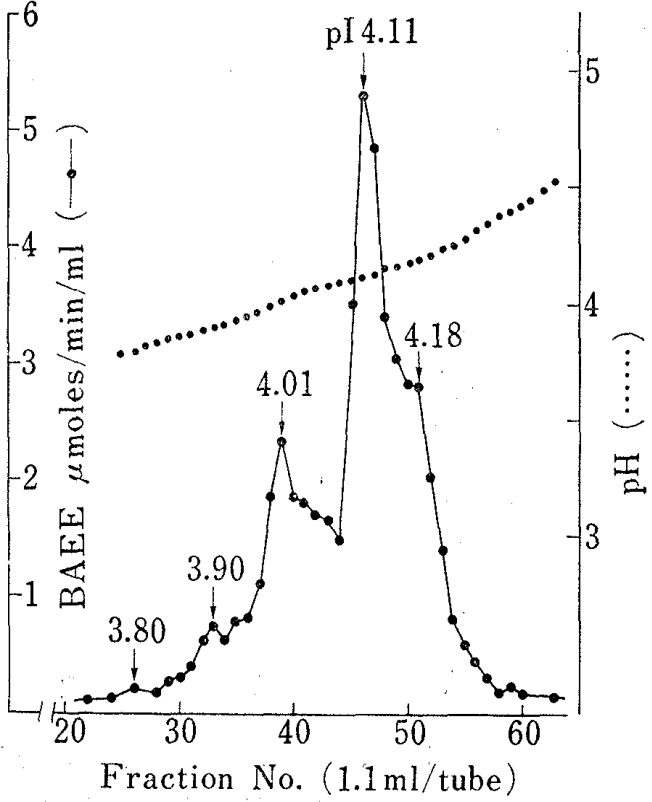

Fig. 2. Isoelectric Focusing of a Preparation of Hog Panc. K., KK-2

KK-2: $0.69 A_{280}$ (1 $186 \mathrm{KU} / A_{280}, 113$ BAEE $\mu$ moles/ $\min / A_{280}$ ) Ampholine: $\mathrm{pH} 3-5$, focusing: $500 \mathrm{~V}, 24$ $\mathrm{hr}, 4^{\circ}$

The activity recovery was $96 \%$.

\section{Further Experiments for the Homogeneity of Hog Panc. K.}

The above conclusion was further ascertained by the following experiments. All of the bracketed fractions of Fig. 1 were mixed and gel-filtered through a Sephadex G-75 column $(2.5 \times 95 \mathrm{~cm})$ with deionized water. The active, break-through peak was lyophilized, and named KY-3M. This preparation gave only a single band in disc electrophoresis (B of Fig. 4). Three groups of bracketed fractions in Fig. 3 were also pooled separately, gel-filtered, and lyophilized by the same procedure as to prepare KY-3M. These preparations were named $\mathrm{KZC}-\mathrm{F}_{1},-\mathrm{F}_{2}$ and $-\mathrm{F}_{3}$ respectively. Each one of these showed a single protein band in disc electrophoresis as shown in Fig. 5 (B-D), and even if $\mathrm{KZC}-\mathrm{F}_{2}$ and $-\mathrm{F}_{3}$ or $\mathrm{KZC}-\mathrm{F}_{1}$

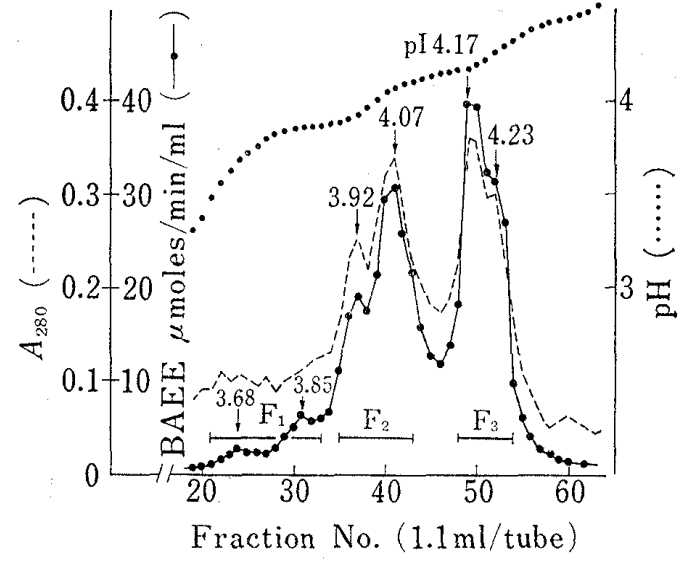

Fig. 3. Isoelectric Focusing of a Preparation of Hog Panc. K., KZC-150

KZC-150: $3.6 \mathrm{mg} 998 \mathrm{KU} / \mathrm{mg}$, 152 BAEE $\mu$ moles/ $\mathrm{min} / \mathrm{mg}$ ) Ampholine: $\mathrm{pH} 3-5$, focusing: $500 \mathrm{~V}, 24$ $\mathrm{hr}, 4^{\circ}$

The activity recovery was $96 \%$. and $-F_{3}$ were mixed and electrophoresed, the bands were single ( $E$ and $F$ of Fig. 5).

From the above results, it appears that the multiple components of Hog Panc. $\mathrm{K}$. with pI 3.68-4.23 have a similar migration distance in disc electrophoresis $(\mathrm{pH} 8.9,7 \%$ polyacrylamide gel). Therefore, it is suggested that disc electrophoresis to be performed under the above normal conditions will be insufficient to examine whether they are separated from one another.

\section{Gel Isoelectrofocusing of Hog Panc. K.'s}

Figure 6 shows the results of this experiment. Both of KK-2 and KZC-150 were separated into 2 main and 5 faint bands, and $\mathrm{KZC}-\mathrm{F}_{1},-\mathrm{F}_{2}$ and $-\mathrm{F}_{3}$ gave 2 bands at the positions expected 


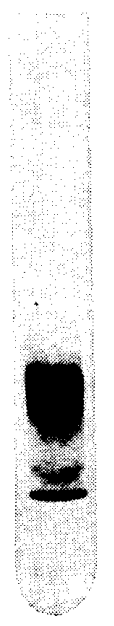

A

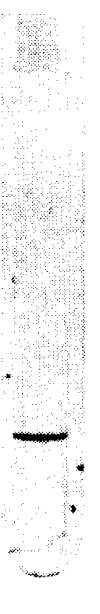

B

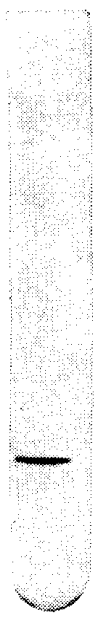

C

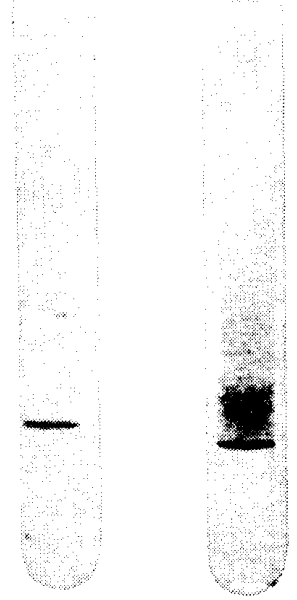

E

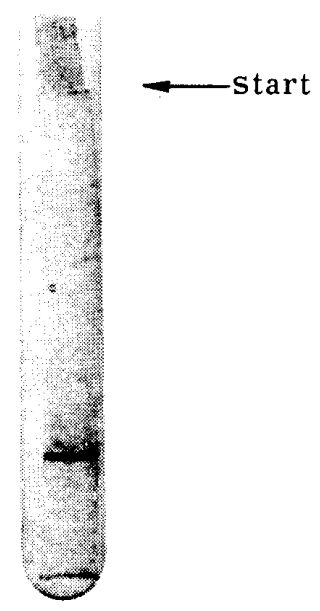

F

Fig. 4. Disc Electrophoretic Patterns of Various Kallikrein Preparations

A: KY-3 $(300 \mu \mathrm{g})$, B: KY-3M $\left(0.03 A_{280}\right), \mathrm{C}: \mathrm{KK}-2\left(0.03 A_{280}\right), \mathrm{D}: \mathrm{KZC}-150(30 \mu \mathrm{g})$,

E: HUK $(75 \mu \mathrm{g}), \mathrm{F}: \mathrm{HSK}\left(0.03 A_{280}\right)$

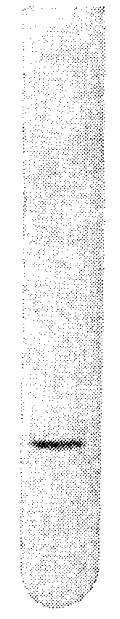

A

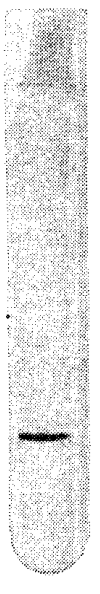

B

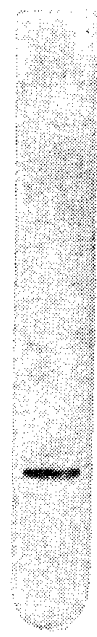

C

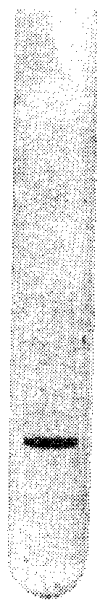

D
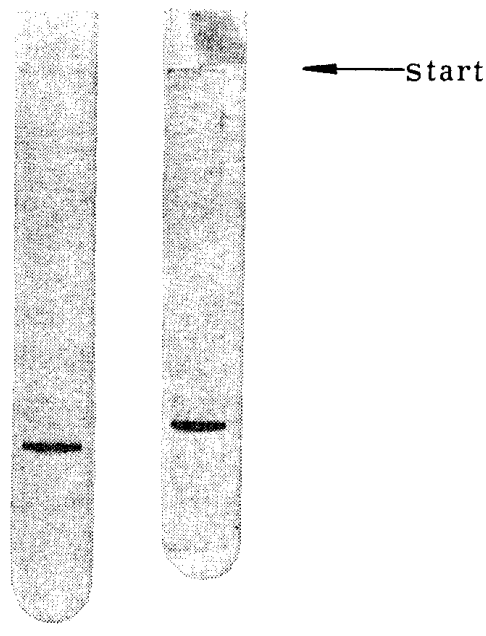

E

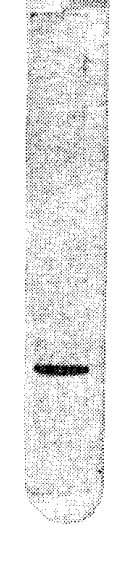

F

Fig. 5. Disc Electrophoretic Patterns of KZC-150, KZC-F $, \mathrm{KZC}_{1} \mathrm{~F}_{2}, \mathrm{KZC}-\mathrm{F}_{3}$ and the Combinations

A: KZC-150 $(30 \mu \mathrm{g}), \mathrm{B}: \mathrm{KZC}-\mathrm{F}_{1}\left(0.015 A_{280}\right), \mathrm{C}: \mathrm{KZC}-\mathrm{F}_{2}\left(0.03 A_{280}\right), \mathrm{D}: \mathrm{KZC}-\mathrm{F}_{3}\left(0.03 A_{280}\right)$, $\mathrm{E}: \mathrm{KZC}-\mathrm{F}_{2}\left(0.015 A_{280}\right)$ plus $\mathrm{KZC} \mathrm{F}_{3}\left(0.015 A_{280}\right), \mathrm{F}: \mathrm{KZC}-\mathrm{F}_{1}\left(0.015 A_{280}\right)$ plus $\mathrm{KZC}-\mathrm{F}_{3}$ $\left(0.015 A_{280}\right)$

from their pl's shown in Fig. 3. The latter result suggests that even if several components of Hog Panc. K. are considerably separated from one another by isoelectric focusing as shown in Fig. 3, an active peak still contains a few components with slightly different pI values.

\section{Results for HUK}

The first preparation of HUK (2.5 KU/mg) was submitted to isoelectric focusing (Fig. 7). Three to five active peaks were found in the range of pI 3.7-4.3 (at $\left.10^{\circ}\right)$.

The second preparation of HUK $(22.5 \mathrm{KU} / \mathrm{mg})$ was contaminated with small amounts of impurities migrated above the distinct band of HUK in the gel tube (E of Fig. 4). Gel isoelectrofocusing of the preparation was tried, but was unsuccessful because of some reason not identified as yet. The substrate specificity of HUK is listed in Table I. 


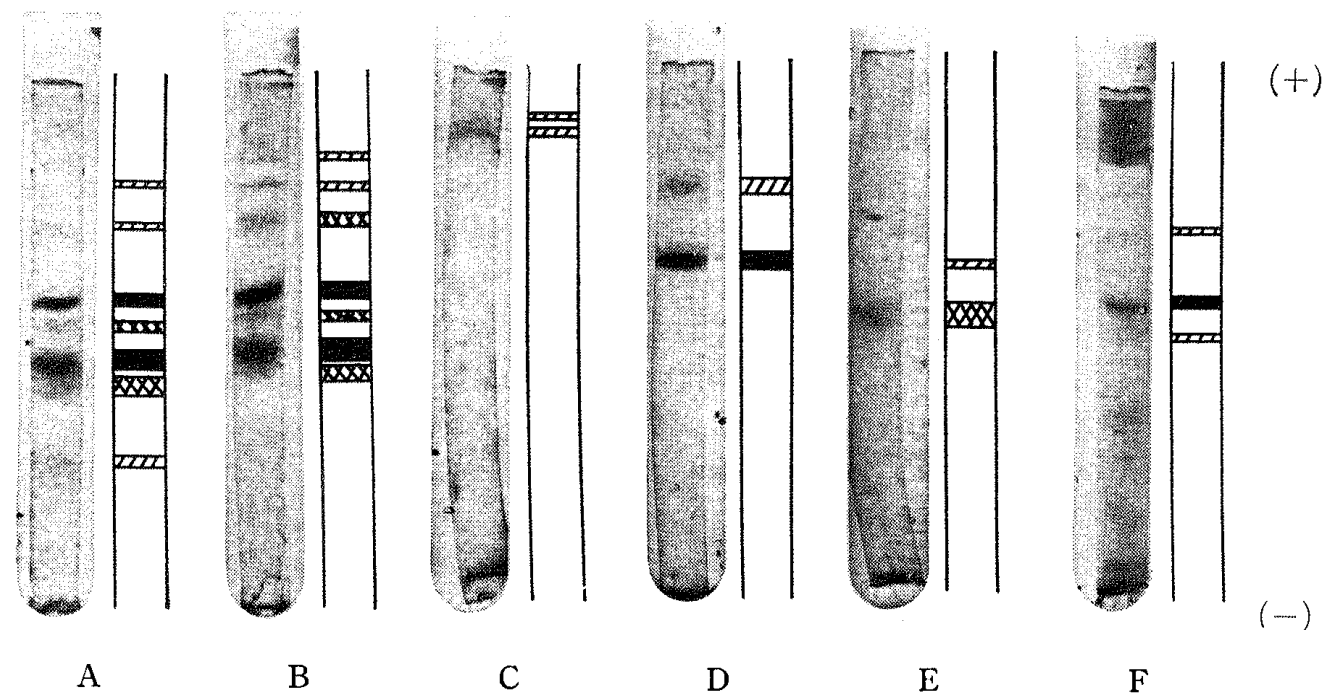

Fig. 6. Gel Isoelectrofocusing of Various Kallikrein Preparations

A: KK-2 $\left(0.03 A_{280}\right)$, B: KZC-150 $(30 \mu \mathrm{g})$, C: KZC-F $\left(0.01 A_{280}\right)$, D: KZC-F $\left(0.03 A_{280}\right), \mathrm{E}: \mathrm{KZC}-\mathrm{F}_{3}\left(0.03 A_{280}\right), \mathrm{F}: \mathrm{HSK}\left(0.03 A_{280}\right)$

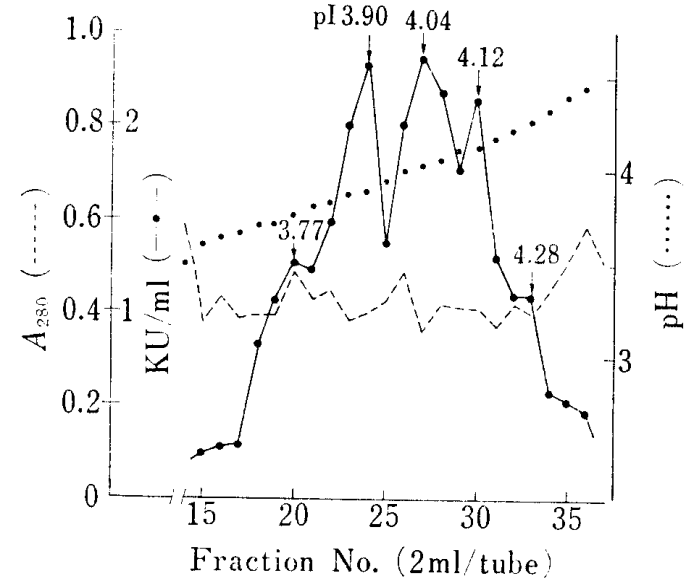

Fig. 7. Isoelectric Focusing of partially Purified HUK

HUK: $28 \mathrm{mg}(2.5 \mathrm{KU} / \mathrm{mg})$, Ampholine: $\mathrm{pH} 3-5$, focusing: $400 \mathrm{~V}, 48 \mathrm{hr}, 10^{\circ}$

The activity recovery was $81 \%$.

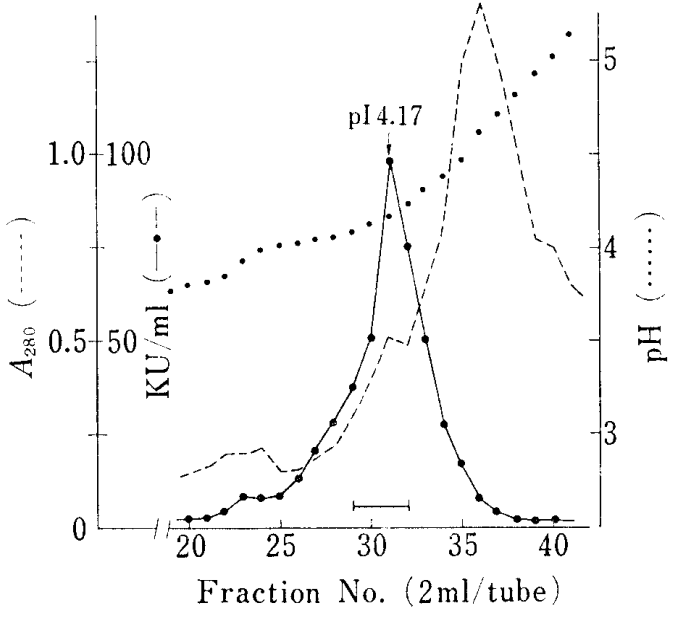

Fig. 8. Isoelectric Focusing of partially Purified HSK

HSK: $6.3 \mathrm{ml}\left(160 \mathrm{KU} / \mathrm{ml}, 2.6 A_{280} / \mathrm{ml}\right)$, Ampholine: $\mathrm{pH} 3-5$, focusing: $400 \mathrm{~V}, 48 \mathrm{hr}, 10^{\circ}$ The activity recovery was $94 \%$.

\section{Results for HSK}

The partially purified preparation of HSK (see Material and Method) was further purified as follows. It was submitted to isoelectric focusing (Fig. 8). In the case of HSK, a single peak was found around pI 4.2.

The four active fractions indicated in Fig. 8 were combined, and gel-filtered through a Sephadex G-25 column $(2.5 \times 40 \mathrm{~cm})$ with $0.02 \mathrm{~m}$ ammonium formate $(\mathrm{pH} 6.0)$ at $4^{\circ}$. Protein fractions were combined and dialyzed overnight against deionized water at $4^{\circ}$. This preparation of HSK $(21.5 \mathrm{ml})$ showed $28.8 \mathrm{KU} / \mathrm{ml}$ and $0.052 A_{280} / \mathrm{ml}$, so that its specific activity was $554 \mathrm{KU} / A_{280}$. Thus HSK was purified 1480 -fold and with the activity recovery of $29 \%$ through the whole procedure. HSK obtained was homogeneous in disc electrophoresis (F of Fig. 4); however, in gel isoelectrofocusing two, very faint bands were observed besides that of HSK (F of Fig. 6). Substrate specificity of the preparation is listed in Table I. 


\section{Substrate Specificities}

In Table I, the activities against various substrates of each sample of three kinds of glandular kallikrein are summarized. Bovine trypsin and $\alpha$-chymotrypsin in Table I were assayed as reference enzymes. Kallikreins had in general strong vasodilator activities in contrast with their esterolytic activities, while trypsin was quite contrary. Three preparations of Hog Panc. K. showed 10-20 times stronger activities to BAEE than to TAME. With respect to this, trypsin showed the contrary relationship. HUK and HSK seemed to be more esterolytic to TAME than to BAEE. Caseinolytic activities of these kallikreins were weak or not detectable, so that caseinolysis would not be an intrinsic activity of glandular kallikreins. That of KY-3 could be due to a contaminant, which is assumed to be chymotrypsin from the BTEE hydrolysis shown by this preparation. Further, since the activities of the kallikreins toward BApNA and BTEE were negligible, the activities on these substrates are also not intrinsic to glandular kallikreins.

TABle I. Substrate Specificities of Three Glandular Kallikreins ${ }^{(\omega)}$

\begin{tabular}{|c|c|c|c|c|c|c|}
\hline \multirow{2}{*}{ Enzymes } & \multirow{2}{*}{$\mathrm{KU} / \mathrm{mg}$} & \multicolumn{3}{|c|}{$\mu$ moles $\left./ \mathrm{min} / \mathrm{mg}^{b}\right)$} & \multirow{2}{*}{$\mathrm{BTEE}^{\mathrm{BTE}}$} & \multirow{2}{*}[\mathrm{TU}]{$_{\mathrm{mg}}^{\left.\mathrm{cas}^{c}\right)}$} \\
\hline & & BAEE & TAME & $\mathrm{BA} p \mathrm{NA}$ & & \\
\hline \multicolumn{7}{|l|}{ Hog Panc. $\mathrm{K}$. } \\
\hline $\mathrm{KY}-3$ & 109 & 11 & 1.0 & 0.002 & 2.7 & 0.98 \\
\hline$\left.K K-2^{d}\right)$ & 1186 & 113 & 5.6 & 0.005 & 0.06 & $\mathrm{ND}^{e)}$ \\
\hline KZC-150 & 998 & 152 & 6.2 & 0.018 & 0.20 & ND \\
\hline HUK & 22.5 & 0.24 & 0.30 & ND & ND & $\mathrm{ND}$ \\
\hline $\mathrm{HSK}^{d)}$ & 554 & 4.6 & 5.2 & $\mathrm{ND}$ & ND & ND \\
\hline Trypsin & 0.45 & 28 & 122 & 0.74 & 0.28 & 3.1 \\
\hline$\alpha$-Chymotrypsin & 0.15 & ND & ND & ND & 34 & 1.2 \\
\hline
\end{tabular}

a) A part of the values in the table has been cited from the previous report. ${ }^{10 b}$ )

b) determined at $25^{\circ}, \mathrm{pH} 8.0$

c) Kunitz's unit $\left.{ }^{15}\right)$

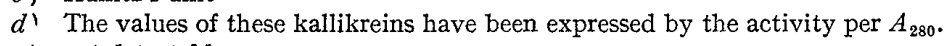

e) not detectable

\section{Discussion}

Hog Panc. K. (KK-2) purified by our previous method ${ }^{8 c)}$ showed a homogeneous protein pattern in disc electrophoresis (C of Fig. 4). Isoelectric focusing (Fig. 2) and gel isoelectrofocusing (A of Fig. 6), however, separated KK-2 into 5-6 kallikrein components with pI 3.8-4.2. Therefore, even if the previous preparation gave a single band in disc electrophoresis, ${ }^{8 c}$ it could be possibly supposed to have those several components.

The activity of partially purified Hog Panc. K., KY-3, was fractionated into several peaks in isoelectric focusing (Fig. 1), so that this preparation would be also composed of several kallikrein components. However, these components (contained in $\mathrm{KY}-3 \mathrm{M}$ ), once fractionated as above, could not be distinguished mutually in the migration distance in disc electrophoresis (B of Fig. 4). This finding was also recognized clearly on KZC-150. This preparation which was homogeneous in disc electrophoresis was separated into two main and one subsidiary (more acidic) fractions viz. $\mathrm{KZC}-\mathrm{F}_{2},-\mathrm{F}_{3}$ and $-\mathrm{F}_{1}$ in isoelectric focusing (Fig. 3). Two of them were combined and disc-electrophoresed; however, they were not distinguishable from each other and gave only one protein band ( $\mathrm{E}$ and $\mathrm{F}$ of Fig. 5). On the other hand, in gel isoelectrofocusing, the above three fractions were distinguished, being further divided into fine components respectively (C-E of Fig. 6). From these results, in the examination of the real homogeneity of Hog Panc. K., gel isoelectrofocusing or isoelectric focusing is preferable to disc 
electrophoresis. This conclusion was also supported by the results of KK-2 (Fig. 2, 4 and 6) and our other results. ${ }^{21)}$

Two kinds of Hog Panc. K., kallikreins A and B, have been obtained by several investigators, ${ }^{3-5,7)}$ and it has been reported that those further comprised several kallikrein components respectively. ${ }^{4 b, c, 7)}$ On the other hand, Moriya, et al. reported the homogeneous preparations of Hog Panc. K. obtained by different methods. ${ }^{2,8)}$ This apparently confused situation may be explained as follows. The kallikrein preparations of Moriya, et al. isolated by preparative electrophoresis $2,8 a, b)$ were the kallikrein B fraction and that like KK-2 which was prepared by hydroxyapatite chromatography ${ }^{8 c}$ ) was the mixture of kallikreins A and B. Detailed studies on the multiple components of Hog Panc. K. and the relationship between those and kallikreins $\mathrm{A}$ and $\mathrm{B}$ are now in progress in our laboratory.

Moriya, et al. isolated HUK, ${ }^{8 b}$ ) and Pierce has already mentioned two components of HUK. ${ }^{22)}$ We, however, detected 3-5 components with pI 3.8-4.3 (Fig. 7). It has not been clarified as yet which of the components shown in Fig. 7 correspond to their HUK's. Such multiplicity of HUK may result from the difference of sialic acid content of each component as Hog Panc. K. ${ }^{4 b)}$ or the materials in urine attaching to the components.

Purified HSK was homogeneous in disc electrophoresis (F of Fig. 4) but did not seem to be completely homogeneous because of faint protein bands detected by gel isoelectrofocusing (F of Fig. 6). Although 4 and 8 enzymes resembling kallikrein were found from the submandibular glands of rat and hog respectively, ${ }^{23)}$ we detected only a single, focused peak of HSK in the present and previous works. ${ }^{18 a}$ ) HSK would be composed of one active component, and so the above faint bands appeared to be biologically inactive contaminants. At any rate, gel isoelectrofocusing is a good technique to examine the homogeneity of glandular kallikrein.

Acknowledgement We wish to thank Mr. A. Kato, Lederle (Japan), Ltd., for the preparation of Hog Panc. K., K.K-2, and Miss H. Fukushima for her valuable advices for the purification of HSK. We are aiso qrateful to Drs. C. Kutzbach and G. Schmidt-Kastner, Bayer AG, Germany, for the kind supply of highly purified Hog Panc. K., KZC-150.

21) Y. Hojima, C. Moriwaki and H. Moriya, Chem. Pharm. Bull. (Tokyo), 23, 1128 (1975).

22) J.V. Pierce, "Handbook of Experimental Pharmacology," Vol. XXV, ed. by E.G. Erdös, SpringerVerlag, Berlin, 1970, p. 21.

23) T.O. Ekfors, P.J. Riekkinen, T. Malmiharju and V.K. Hopsu-Havu, Z. Physiol. Chem., 348, 111 (1967); F. Fiedler, B. Müller and E. Werle, ibid., 351, 1002 (1970). 